Aletria, Belo Horizonte, v. 29, n. 1, p. 127-139, 2019

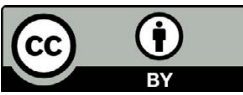

\title{
Rãs: a mimesis de Dioniso
}

\section{Frogs: The Mimesis of Dionysus}

\author{
Elisana De Carli \\ Universidade Federal de Santa Catarina, Florianópolis, Santa Catarina / Brasil \\ elisana.carli@ufsc.br
}

Resumo: A leitura das peças do comediógrafo Aristófanes (c.450-385 a.C.) permite identificar um assunto recorrente: o fazer teatral e seus elementos. Em Rãs representase uma viagem protagonizada por Dioniso, deus do teatro, preocupado com os ditames e os caminhos de sua arte e empenhado em resgatar a glória da tragédia. Para tanto, demarcada por duas fases no enredo e na estrutura da peça, o personagem encena seu caráter hibrido e as possibilidades de transformação que refletem elementos da composição teatral. A partir disso, focalizaremos, para este estudo, o modo de apresentação desse repertório, destacando a correlação entre a estrutura e o conteúdo deste texto teatral, salientando a composição estética do autor e da obra, através desse personagem que é o fio condutor e mote da peça, entendida como objeto estético, cênico e metateatral.

Palavras-chave: Aristófanes; Rãs; mimesis; teatro; comédia; tragédia.

Abstract: The reading of the plays by the comediographer Aristophanes (450-385 B.C.) allows us to identify a recurring subject: the theatrical activity and its elements. In Frogs, a play which depicts a trip took by the theater's god Dionysus, worried about the ways and rules of his art, and committed to recovering the tragedy's glory. In order to do so, by setting two phases in the play's plot and structure, the character stages his hybrid disposition and transformation possibilities that reflect elements of theatrical composition. Thus, this study focuses on how this repertoire was presented, highlighting the correlation between structure and content of the theatrical text, emphasizing the aesthetic composition of the author and work through Dionysus, who conducts the play as an aesthetic, scenic, and metatheatrical object.

Keywords: Aristophanes; Frogs; mimesis; theater; comedy; tragedy. 
Encenada em 405 a.C., Rãs conquista o primeiro lugar nas Leneias. Com um texto que explora a visualidade do palco e dinamiza o espetáculo, Aristófanes segue a linha de tratar da composição teatral, temática que aparece como uma constante em sua produção, com gradações variadas, destacando-se em Mulheres que celebram as Tesmofórias, apresentada em 411 a.C., e atingindo o ápice em Rãs. Se naquela o foco está em um texto que impulsiona o espetáculo pela sobreposição de personagens, pelo intertexto parodístico de tragédias de Eurípides para provocar o riso e testar o conhecimento do espectador sobre teatro, em Rãs o cerne também está no teatro, especificamente no fazer teatral de Ésquilo e de Eurípides; porém a composição estética é muito distinta daquela da peça de 411, diferenciando-se quanto a estrutura, atuação do coro, e a forma de abordar o tema. Em vista disso, interessa-nos observar, pela análise do personagem do deus do teatro, o modo de apresentação desse conteúdo em Rãs.

Entretecendo estrutura e conteúdo, essa comédia se expande e se revela em uma dinâmica de aparências, um fluxo de níveis de significados que são atribuídos na própria cena, compondo uma fluência entre o parecer e o ser, demarcando e iluminando a mimesis teatral. $\mathrm{O}$ elemento que fomenta e avança neste processo é Dioniso: deus do teatro e personagem dessa comédia. Assim, se o faz é por competência e pertencimento, pois é a sua divindade, mas também, e fundamentalmente, pela atuação do personagem criado por Aristófanes.

O conteúdo relacionado ao teatro, tornado meio e objeto da peça, é apontado já na lista de personagens: Dioniso, Ésquilo, Eurípides. Este último é figura recorrente na obra aristofânica, através de menções ao seu estilo trágico ou como personagem em diversas ${ }^{1}$ comédias. Esse é um dos passos tradicionais de Aristófanes, contudo, não explorado do mesmo modo, como reitera MacDowell, ${ }^{2}$ visto que cada texto do comediógrafo tem uma proposição especifica, mantendo elementos de constância. Além de personagens relacionados ao teatro, no verso 15 são mencionados três comediógrafos da época - Frínico, Lícis e Amípsias - que, segundo Xântias, se valiam do recurso que está em curso para o público rir: um escravo carregado de tralhas e cacarecos a contar piadas de sempre. A repetição dessa estratégia é recusada pelo patrão/deus do teatro: ninguém

\footnotetext{
${ }^{1}$ Acarnenses, Cavaleiros, Nuvens, Vespas, Paz, Lisístrata, Mulheres que celebram as Tesmofórias.

${ }^{2}$ MACDOWELL. Aristophanes and Athens.
} 
mais aguenta, "poupa-nos" (v.4; $6 ; 12 ; 18)$ : a abertura do prólogo sinaliza a temática, uma discussão sobre os artifícios do teatro, aqui cômicos (vv.1-30). Ainda, o objetivo da peça é claro: Dioniso quer resgatar Eurípides do mundo dos mortos, pois os poetas que atuam àquele momento não são suficientemente bons, qual a virtuose de Eurípides (vv.66-72). Antes dessa declaração, o riso é instado a partir de recursos tradicionais da comédia que o autor sabe explorar com novas proposições, desenvolvendo cenas que aproveitam os recursos do teatro pautando-se, além das palavras, também nos figurinos, cenários, alimentando de modo recíproco os sentidos visuais e auditivos do espectador/leitor que acompanha as ações que ocorrem no tempo presente e no espaço visível do palco.

Tem-se, assim, a linha de ação do personagem central, Dioniso: chegar ao Hades a fim de resgatar o poeta dos poetas. Para tanto, ele aciona os demais personagens e por eles é acionado. Esses objetivos são performados de modo diverso e apresentam dois momentos diferentes na peça, o que entendemos como resultante da estratégia estética de Aristófanes, que entrelaça estrutura e conteúdo explorando-os e destacando os vieses de composição da arte do teatro. Analisando-se seus elementos estruturais, é possível considerar a constituição da peça em duas partes, como afere Garcia López ao observar a existência de dois prólogos em $R \tilde{a} s$ - o primeiro correspondente aos versos 1 a 322 e o segundo, aos versos 738 a 813 , ambos com ritmo e objetivo diferentes. ${ }^{3}$ "[A] razão mais verossímil para repetição deste elemento teatral seria para introduzir e explicar as razões de enfrentamento entre Ésquilo e Eurípides, para preparar e informar o espectador." 4 Para Russo, ${ }^{5}$ a organização da peça é entendida como dois atos distintos em uma comédia que demonstra profundos recursos dramáticos de Aristófanes.

Essa disposição da estrutura da comédia é mais uma faceta da exploração do tema da composição do gênero dramático por Aristófanes e demonstra a liberdade de criação e uso das normas e feitios da tradição; ${ }^{6}$ nas palavras de Silva, "um técnico consciente da arte que cultivava".?

${ }^{3}$ GARCIA LÓPEZ. Los dos prólogos de Ranas de Aristófanes.

${ }^{4}$ GARCIA LÓPEZ. Los dos prólogos de Ranas de Aristófanes, p. 213.

${ }^{5}$ RUSSO. Aristophanes: an author for the stage, p. 241.

${ }^{6}$ Cf. ARISTÓFANES. Rãs; SILVA. Ensaios sobre Aristófanes; GARCIA LÓPEZ. Los dos prólogos de Ranas de Aristófanes; e RUSSO. Aristophanes: An Author for the Stage. ${ }^{7}$ SILVA. Ensaios sobre Aristófanes, p. 11. 


\section{Encontrar o caminho: revelar o personagem}

A primeira parte é caracterizada pela busca, pela tentativa de encontrar o caminho empreendida por Dioniso e Xântias para chegar ao Hades. Esse percurso é marcado pela mistura de esferas, de referências, de funções: no prólogo, abre a cena no palco um escravo carregado de bagagens, montado em um burro, e um patrão a trajar um manto de cor laranja, habitual das cortesãs.

Dioniso, ao descer aos ínferos - delimitação da primeira parte -, configura a catábase, ${ }^{8}$ movimento de descida, na qual explora "ações de caráter baixo", caracterizando um dos níveis do gênero cômico, expondo atitudes demasiadamente humanas para um deus. Este percurso de descoberta, jornada e chegada ao Hades se materializa "cômico/risível", pois temos um deus titubeante, que não se percebe e não é percebido, dinâmica que nos remete à ideia do processo de preparação de uma encenação, a um período de ensaios: não tem identidade firmada, não sabe exatamente seu papel, alterna funções e tarefas com Xântias, - como em testes e ensaios de "composição do personagem".

Essa dinâmica de troca de personagens, de um exercício cênico lembrando-nos a ideia de um ensaio aberto, podendo transmitir a sensação de improviso, é de fato um objeto estético estruturado, explorando os recursos do gênero cômico. Após vivenciar diferentes experiências, "viver" diferentes papéis: travestir-se de Hercules, carregar bagagens, remar, apanhar de Caronte, enervar-se com as rãs, fazer papel de deus, fazer papel de escravo, Dioniso alcança parte do objetivo ao encontrar os tragediógrafos e reconhecer seu papel: deus do teatro. Em cena, encena um percurso de construção - uma mimesis. Como deus do teatro revela/ expõe/vive a sua arte, a composição da apate (ilusão) a partir da ação em cena no palco visível, e por seu portento teatral constitui-se no ir e vir, estar, parecer, ser; capacidade e potencialidade divina: transformarse; capacidade e potencialidade do teatro; do ator. Dioniso, em cena, se revela e revela sua arte. Aristófanes, ao estabelecer este trânsito, oferece

\footnotetext{
${ }^{8}$ Considerado um topos na literatura antiga; “os que descem em 'catábase' aos infernos, fazem-no quase sempre para averiguarem, o que de pouco claro se lhes afigura na vida terrena, ou para cumprirem qualquer missão de importância (Hércules), em geral em favor de qualquer pessoa ou comunidade humana" (ROSADO FERNANDES. Catábase ou descida aos infernos alguns exemplos literários, p. 347). Para este autor, na proposição de Aristófanes para Rãs o aspecto sagrado do Hades é destituído.
} 
através de um objeto estético considerações acerca do estado da arte, especificamente, tomando o próprio teatro como objeto estético e de análise. Com uma estrutura bipartida amalgamada em consonância com o conteúdo, o comediógrafo apresenta Dioniso, deus do teatro, intencionado a resgatar a glória da tragédia, indo em busca do "poeta dos poetas" que habita o Hades, onde se encontra o trio Ésquilo, Sófocles, Eurípides, as grandes vozes do gênero.

Aida aos ínferos parece fomentar o aspecto inferior do personagem Dioniso, demarcando as "ações de caráter baixo" configurador do gênero cômico, potencializado pela exploração da perspectiva visual dos personagens, seus figurinos, atuações, cenário. Nesta primeira parte, amparado por Xântias e Hércules, Dioniso convoca o público a rir, a discutir e a avaliar a noção de identidade que reverberam significados em diferentes aspectos: teatral, histórico, social, religioso, expondo as fragilidades de cada um, para além e para aquém das expectativas. Dioniso e Hercules são irmãos, são seres híbridos, formados pela conjunção da divindade com o humano, manifestando habilidades diversas. Dioniso, ao trocar de papel com o escravo/patrão/escravo, reitera o heterogêneo, a mistura, o mortal e o divino, simbolizados também pelo figurino, signo visual que instiga e aponta significados.

Então, a simbologia de Dioniso na peça se espalha e se espelha pela ideia do hibrido - Dioniso ${ }^{9}$ é um deus híbrido: divino/humano; grego/ bárbaro; masculino/feminino; cômico/trágico. Nesta peça de 405 a.C., o fazer teatral, pautado na potencialidade do palco, manifesta na maior utilização do espaço cênico visível com ações e decisões no aqui/agora, demarca "experimentos e movimentos" do teatro; se característicos na comédia por sua "aparente" maior liberdade, porém aferidos em tragédias de Eurípides, especialmente em Helena, Andrômeda, ${ }^{10}$ a tal ponto, apenas

\footnotetext{
9 "Na cultura grega, tão delimitada em certos sentidos, Dioniso confunde as fronteiras. E não se trata de forma alguma de uma coisa contraditória, é uma coisa complementar. $\mathrm{Na}$ medida em que as fronteiras entre homem e mulher, entre grego e bárbaro, entre homens e deuses estão marcadas com tanta precisão, deixa-se um lugar para a necessidade de explodir o sistema em determinados momentos." (VERNANT. Um teatro da cidade, p. 351).

${ }^{10}$ Cf. EURÍPIDES. Helena; SILVA. Crítica do teatro da comédia antiga; SILVA. Ensaios sobre Aristófanes; SILVA. Ensaios sobre Eurípides; WRIGHT. Euripides' escape-tragedies: a study of Helen, Andromeda, and Iphigenia among the Taurians. Da peça Andrômeda restaram apenas fragmentos; Helena se encontra completa, com tradução de Alessandra Cristina Jonas Neves Oliveira (cf. EURÍPEDES. Helena).
} 
para exemplificar, suscitou polemica entre os estudiosos sobre a própria classificação como gênero trágico por se distanciar do padrão tradicional. Esse cruzamento de elementos entre a tragédia e a comédia demonstra a acuidade de elaboração estética dos dramaturgos e uma produção variada do teatro, tendo como parâmetro apenas os textos que chegaram até nós, uma porcentagem mínima do que foi a produção à época.

Neste ínterim de mistura, característica reiterada de modos variados nesta primeira parte, demarcada pelo percurso até o Hades, nem as "devotas" rãs reconhecem o deus a quem celebram, nem o invocado reconhece as celebrantes de seu ritual (vv.210-268). O coro de rãs, que tanto debate suscita entre os comentadores, ${ }^{11}$ simbolicamente também vive entre revelar-se e esconder-se, por seu habitat, o lamaçal, o charco, um meio híbrido entre a terra e a água, qual Dioniso, marcado pelas antíteses e transformações. Vale lembrar que é este coro que dá título à comédia, inferência de destaque, e remete à tradição de nomear as peças pela identidade do coro, que neste texto tem apenas uma apresentação. Sobre este descompasso entre a importância do título e a atuação singular das rãs, Vieira conjectura que uma intenção possível para tal descompasso seria:

contrariar a expectativa do público e do leitor. Onde imaginamos encontrar certo sentido, deparamo-nos com outro totalmente diverso. Um caminho é acenado, outro é percorrido. Não seriam esses giros um dos pilares das inversões carnavalescas? Tal dinâmica depende da originalidade da linguagem e da novidade dos episódios, e nisso Aristófanes foi mestre. ${ }^{12}$

O caráter de originalidade é também destacado por Vieira na composição inventiva pelo comediógrafo de vocábulos inusitados como o coaxar das rãs: "Brekekekex coax. Brekekekex coax." (v.210)

As rãs entoam o canto ritualístico a Dioniso, a quem invocam (v.215) durante a travessia do lago, na qual a figura divina assumiu o papel de remador, sob a direção de Caronte. Nessa passagem que apresenta Dioniso, Caronte e o coro de rãs, destaca-se uma composição

\footnotetext{
${ }^{11}$ Sobre a possível presença deste coro de rãs no palco, seu figurino, sua função e representatividade no texto, cf. SIFAKIS. Parabasis and Animal Choruses; RUSSO. Aristophanes: An Author for the Stage; GRIFFITH. Aristophanes' Frogs.

${ }^{12}$ ARISTÓFANES. As rãs, p. 15.
} 
cênica de signos verbais e não verbais, explorando a visualidade e a oralidade na busca pelo fazer rir o público, como o não reconhecimento, pelos personagens em cena, de suas identidades e de elementos óbvios, facilmente reconhecíveis pelo espectador, somando-se a cobrança monetária para a travessia, a incompetência náutica de Dioniso, o enfrentamento do remador com as rãs, em um embate de coaxar. Esse fluir de níveis e de funções, demarcado pelo espaço cênico, pelos personagens e suas falas, reitera a mobilidade como uma das forças de construção do jogo cômico. Tal dinâmica que consideramos como possibilidade do jogo cênico, marcadamente da comédia antiga, é também concebida como um ágon de identidade. ${ }^{13}$

\section{Exercer o personagem}

Da liberdade cômica da primeira parte, que permite a experimentação, surge o caminho, encontra-se o tom do personagem. Dioniso assume seu papel como deus do teatro - sendo reconhecido pelos seus pares, como Plutão - e é elencado como juiz da contenda entre os cadáveres de Ésquilo e Eurípides, para ser laureado como o melhor dos poetas (vv. 760-790).

Nesta segunda parte, não há mais misturas de níveis e de personagens. Deuses e mortais assumem suas funções e papeis com clareza, sem dúvidas, defendendo seus posicionamentos durante o desenrolar do julgamento dos tragediógrafos. Essa clareza da defesa reiterada das ações dos personagens, configura uma conformação do gênero trágico. Essa elaboração estética gera uma contraposição à dinâmica da primeira parte e liga-se ao conteúdo proposto para essa comédia; i.e., o resgate da tragédia. Esse arranjo aponta para uma ação crítica e cômica de Aristófanes: a tragédia é salva pela comédia - referência explorada em As mulheres que celebram as tesmofórias, e/ou, a tragédia é salva na comédia.

\footnotetext{
${ }^{13}$ A troca de identidade, Dioniso como Xântias, como Hércules, como um remador, é pontuado por Silva (2007) como um conflito de identidade, calcada em uma leitura histórica. A representação da mistura de níveis, de mundos, onde tudo está em causa, demonstrando a crise na sociedade ateniense, na tradição mitológica e religiosa, correspondente ao ceticismo da época (SILVA. Ensaios sobre Aristófanes, p.169).
} 
Assim, a temática do teatro, com apontamentos de análise teórica e prática, é referenciada não apenas por tomar os tragediógrafos, personalidades históricas, como personagens, mas também pelo adensamento ao "pesar" os versos de cada um dos poetas, ao analisar os estilos de cada tragediógrafo, características que são, efetivamente, identificadas ao longo dos versos 830-1413, materializadas na atuação dos personagens Eurípides, Dioniso, Ésquilo e o coro de iniciados, que compõe o ágon. Essa marca retoma uma característica estrutural das comédias de Aristófanes que são construídas em torno de um ágon (ou dois), onde um personagem tenta convencer o oponente cético, ou dois rivais debatem frente a um júri. Como Griffith destaca, ${ }^{14}$ o processo de argumentação e contra-argumentação é estruturado, geralmente, em uma combinação de ideias sérias, provocativas, distorcidas ou absurdas, pleiteando o humor e, por vezes, o recurso da interação física.

Como pontuamos anteriormente, nessa descida ao Hades não há sacralidade, contudo o objetivo de redenção, o objetivo maior em prol da cidade, parece se efetivar: nos ínferos ocorre a transformação, a revelação. Aristófanes retoma um elemento da epopeia, um topos, satirizando-o, a priori, mas mantem a intenção. Utiliza o referencial da tradição no escopo da comédia, retomando na acepção literal que é o objetivo da catábase, a qual aparece, na primeira parte, como que deformada, invertida. Entretanto, ao final revela-se mais um percurso de parecer/ser, como a criar uma ilusão de cena que depois se revela como mera aparência enganadora, criando um recurso de composição - gerando um reconhecimento. Tem-se, então, o imbricamento de elementos da comédia e da tragédia na composição do drama (ação), do teatro. Essa estrutura bipartida, decorrente da mudança de ritmo, não quebra unidade da peça, e como aponta Silva $(2014,2007)$, Dioniso é fio condutor das ações e do enredo, do início ao fim, completando os objetivos manifestos: chegar ao Hades, resgatar o poeta dos poetas e a glória da tragédia. Esse entendimento também é defendido por Griffith, ${ }^{15}$ ao considerar que a identidade ambígua de Dioniso é vital para o desenrolar da peça, estabelecendo, assim, mais uma ligação entre estrutura e conteúdo.

O motivo inspirador da jornada ao Hades é a leitura da tragédia Andrômeda, a qual fomenta em Dioniso uma paixão euripidiana. $\mathrm{O}$ deus do teatro só pensa em Euripides, como manifesta verbalmente:

\footnotetext{
${ }^{14}$ GRIFFITH. Aristophanes' Frogs, p.169.

${ }^{15}$ GRIFFITH. Aristophanes' Frogs, p.58.
} 
Dioniso: Pois, estava eu na coberta do navio, a ler, cá com meus botões, a Andrômeda, quando de repente uma nostalgia me bate ao coração, sabes lá tu de que maneira!"

Hércules: Uma nostalgia te bate o coração? De que dimensão?

Dioniso: Coisa pequena, pela medida de Mólon. (vv.52-56)

Mesmo Hércules indicando outros tragediógrafos (vv.52-105), Dioniso só tem olhos e ouvidos para o autor que lhe tocou o coração. Vale destacar, no excerto acima, a menção aos elementos de composição do teatro, texto e espetáculo: i) a leitura da peça, indicando alguma forma de circulação do texto teatral e o fortalecimento do ato de ler na sociedade ateniense; ${ }^{16}$ ii) a referência a Mólon, ator que atuara em Andrômeda e outras peças de Eurípides e referido como homem de alta estatura, ${ }^{17}$ alvo da comparação de Dioniso.

Mantido o cumprimento dos objetivos de Dioniso, cabe destacar a alteração do foco e da intenção. Do embate entre os tragediógrafos, a indecisão o toma, pois "um oferece sapiência, enquanto o outro dá prazer" (v.1414). Arremata, então, o deus do teatro: "desci atrás de poeta, tendo em vista a salvação de Atenas, que preserva os festivais teatrais./Comigo levarei quem for capaz de dar/ melhor conselho à cidade." (vv.1418-21). Assim, pela observação das demandas da cidade, a qual atravessa uma crise sem precedentes, Ésquilo tem mais a oferecer no momento (v.1472), como destacam também Plutão e o coro de iniciados no desfecho da peça (v. 1500, v.1530). Esse arremate representa a justaposição da estrutura e do conteúdo, amalgamados à comédia e à tragédia, tangidos ao longo da peça, demonstrando a elaboração estética do comediógrafo, sua mimesis, que nas palavras de Slater, "Aristófanes não está preocupado somente com o estado artístico da tragédia, ele oferece suas comédias como uma forma alternativa de pensar e falar diretamente, não miticamente, sobre Atenas e seus problemas." ${ }^{18}$ Essa perspectiva da proposição de análise

\footnotetext{
${ }^{16}$ Como esclarece a pesquisadora e tradutora Maria de Fatima Silva (ARISTÓFANES. Rãs, p. 41, nota 12).

${ }^{17}$ ARISTÓFANES. Rãs, p. 41, nota 13; ARISTÓFANES. As rãs, p. 23, nota 5. 18 "Aristophanes is not just worried about tragedy's state of artistic health; he offers his own comedy as an alternative way of thinking and talking way directly, not mythically, about Athens and its problems." (SLATER. Spectator politics: metatheatre and performance in Aristophanes, p. 6, tradução nossa)
} 
da elaboração artística amalgamada à outras questões citadinas é característico em Aristófanes e aponta para um dos pilares da comédia que é a temática do cotidiano dos cidadãos, dos assuntos prementes da sociedade. Reiterando essa conformação à Rãs, Trajano Vieira assevera: "A maneira divertidíssima como Aristófanes apresenta o antagonismo dessas duas concepções literárias não obscurece outros temas de $A s$ rãs. Penso nas alusões à decadência do poder ateniense diante de Esparta $\mathrm{e}$ à crise cultural por que passava a cidade". ${ }^{19}$

Deste percurso empreendido pelo deus do teatro, além da crítica à cidade, revela-se vieses da composição da arte teatral: a leitura da peça, a força do espetáculo, o olhar sobre a cidade que abriga o teatro. Aristófanes, sem esquecer o objetivo artístico, valendo-se da capacidade do deus do teatro, apresenta os meandros do fazer do drama, como autor e como esteta. Especificamos o uso do vocábulo esteta pela demonstração de conhecimento da convenção da época, lançando fios de uma teoria incluída no fenômeno teatral, sendo uma especulação com graça/humor, permeada pelo contexto do gênero cômico, não tendo o rigor de um tratado, mas a realidade do fazer é apresentada. Ainda que sem pretensão e/ou denominação de um tratado formal, visto sua efetiva participação nos concursos de comédia, obtendo várias vitórias, Aristófanes é um profissional de teatro, um estudioso de sua arte, demonstrando a liberdade de criação e o uso das normas e estruturas da tradição, tornada visível e vivenciada pelo personagem de Dioniso em Rãs.

\section{Considerações finais}

Nessa comédia, a presença do personagem Dioniso em cena permite uma reflexão acerca do teatro de viés estético, cênico, teórico, histórico sem perder sua função de ser uma comédia. Na primeira parte da peça, atua como um personagem cômico, abordando os recursos usados na comédia (v.1-30); na segunda, como ele próprio, expondo os artifícios usados na tragédia por seus autores, configurando o texto dramático também com matizes de análise teórica da práxis. Exercida por Dioniso, a correlação dessas duas partes evidencia a potência híbrida do teatro.

A estrutura bipartida proporciona uma mudança de ritmo e de tom, mantendo a unidade e a dinamicidade da peça, demonstrando a

${ }^{19}$ ARISTÓFANES. As rãs, p. 13. 
capacidade técnica do poeta/autor, uma das premissas que Aristófanes utilizou nos textos dramáticos como meio e objeto de trabalho, cuja perspectiva, a priori, vê-se "iludida" em uma apate que, inicialmente, apresenta as técnicas habituais da comédia, ou satiriza a tragédia. Ledo (e risível) engano. "Às crianças é o mestre-escola que as ensina e aos adultos são os poetas." (Rãs, v.1054). Aristófanes apresenta um teatro sob o teatro, uma peça que se alicerça sobre os fundamentos do gênero, revelando um teatro sobre o teatro, um teatro que se vê, que é visto, um teatro que vê a cidade. Esses níveis de observação, do "theatron": o lugar de onde se vê, são ofertados por Aristófanes no percurso de Rãs, podendo, talvez, o leitor/espectador reconhecer-se, e qual inspirado pelo deus do teatro: "Ao alcançar a sua definição individual, o deus obtinha também a clarificação do seu papel coletivo."20

Essa potência é também a do jogo cênico. Fomenta níveis de significação, com leituras literais, simbólicas, históricas amalgamadas esteticamente no texto e manifestas no espetáculo, pelo estímulo da capacidade do deus do teatro e que se expressa através de personagens, mas, certamente, pelo poder da poiesis e da mimesis de Aristófanes.

Assim, essa composição cômica se torna, além de objeto estético, um objeto cênico, um texto metateatral. Objeto estético como resultante de uma mimesis; cênico porque retira do texto elementos consistentes para representação cênica, dando destaque ao espetáculo; um texto metateatral, no sentido de trazer à cena o fazer teatral, via temática, personagens, estrutura e recursos cênicos explorados. Em vista disso, o texto cômico se torna, em consequência, um registro histórico e um contributo teórico, ao olhar sobre a produção teatral do período. Retomando esse processo de construção estética, através do referencial crítico proposto por Mostaço (2018), Aristófanes considera o ato e o fato estético, a arte, a técnica, o método; na sua práxis cômica observa a práxis do teatro, notificando sua proposição e entendimento sobre a arte teatral.

${ }^{20}$ SILVA. Ensaios sobre Aristófanes, p. 181. 


\section{Referências}

ARISTÓFANES. As rãs. Tradução, introdução e notas de Trajano Vieira. São Paulo: Cosac Naify, 2014.

ARISTÓFANES. Rãs. Tradução, introdução e comentários de Maria de Fátima Silva. Coimbra: IUC; São Paulo: Annablume, 2014.

EURÍPEDES. Helena. Tradução de Alessandra Cristina Jonas Neves Oliveira. Coimbra: Imprensa da Universidade de Coimbra, 2015. Doi: http://dx.doi.org/10.14195/978-989-26-1047-4. Disponível em: <https:// classicadigitalia.uc.pt/en/livro/helena> . Acesso em: 20 jun. 2017.

GARCIA LÓPEZ, José. Los dos prólogos de Ranas de Aristófanes. In: LOPES FÉREZ. J. (ed.). De Homero a Libanio. Madrid: Ediciones Clásicas, 2005. p. 213-224.

GRIFFITH, Mark. Aristophanes' Frogs. Oxford; New York: Oxford University Press, 2013.

MACDOWELL, Douglas. Aristophanes and Athens. Oxford; New York: Oxford University Press, 1995.

MOSTAÇO, Edelcio. Teatro, o ato e o fato estético. In: .Incursões e excursões. São Paulo: Pequeno Gesto, 2018. p.83-99.

ROSADO FERNANDES, Rául Miguel. Catábase ou descida aos infernos alguns exemplos literários. Humanitas, Coimbra, n. XLV, p. 347-359, 1993. Disponível em: $<$ https://www.uc.pt/fluc/eclassicos/publicacoes/ ficheiros/humanitas45/19_Rosado_Fernandes.pdf $>$. Acesso em: 14 out. 2017.

RUSSO, Carlo F. Aristophanes: An Author for the Stage. London; New York: Routledge, 1994.

SIFAKIS, Gregory Michel. Parabasis and Animal Choruses. London: Athlone Press, 1971.

SILVA, Maria de Fátima S. Crítica do teatro da comédia antiga. Coimbra: INIC, 1987.

SILVA, Maria de Fátima S. Ensaios sobre Aristófanes. Lisboa: Cotovia, 2007. 
Aletria, Belo Horizonte, v. 29, n. 1, p. 127-139, 2019

SILVA, Maria de Fátima S. Ensaios sobre Eurípides. Lisboa: Cotovia, 2005.

SLATER, Niall W. Spectator Politics: Metatheatre and Performance in Aristophanes. Philadelphia: University of Pennsylvania Press, 2002.

VERNANT, Jean-Pierre. Um teatro da cidade. In: . Entre mito \& política. Tradução de Cristina Murachco. São Paulo: Edusp, 2001. p. 347-357.

WRIGHT, Matthew. Euripides' escape-tragedies: a study of Helen, Andromeda, and Iphigenia among the Taurians. Oxford University Press, 2005.

Recebido em: 30 de setembro de 2018.

Aprovado em: 29 de novembro de 2018. 